Volume 19 Nomor 1

\title{
PENGARUH PROMOSI, HARGA DAN DESAIN PRODUK TERHADAP KEPUTUSAN PEMBELIAN SEPEDA MOTOR HONDA BEAT \\ (Studi Kasus: Pengguna Sepeda Motor Honda Beat Pada Masyarakat Kecamatan Medan Tembung)
}

\author{
Peran Simanihuruk \\ Universitas Katolik Santo Thomas Medan Jl. Setia Budi No. 479F, 20132, Indonesia \\ e-mail: cumandiri@gmail.com
}

\begin{abstract}
The purpose of the study was to analyze the effect of promotion, price and product design partially and simultaneously on purchasing decisions and analyze the dominant influence of the three variables on the purchase decisions of Honda Beat motorbikes. Benefits of Research, for companies providing empirical evidence regarding the effect of promotion, price and design on purchasing decisions and providing solutions in the form of suggestions on the management of these variables. The number of samples is 96 respondents, questionnaire data collection methods and documentation, Techniques of multiple linear regression data analysis. The results showed: $Y=2,711+0,268 X 1+0,227 X 2+$ $0,335 X 3$, meaning that promotion, price and product design had a positive influence on purchasing decisions of Honda Beat motorbikes in Medan Tembung Subdistrict. With the $t$ test and the F test the three independent variables have a positive and significant influence partially and simultaneously on purchasing decisions. Based on the magnitude of the regression coefficients, it turns out that the three variables that have the dominant influence on purchasing decisions are product design variables. So it is hoped that the Company will be able to maintain and improve the competitiveness of its products, affordable prices, innovative Honda product designs.
\end{abstract}

Keywords: Promotion, Price, Product Design and Purchasing Decision

\section{PENDAHULUAN}

Konsumen merupakan target sasaran perusahaan yang menawarkan barang dan jasa. Persaingan bisnis yang semakin tajam antar kompetitor yang terlibat langsung merupakan ancaman yang sering ditemui oleh perusahaan baik produk lokal, nasional dan internasional. Pada era pasar bebas yang sudah diperlakukan dihadapkan pada tantangan yang lebih berat. Perusahaan dituntut lebih kreatif dan inovatif untuk memanfaatkan peluang yang ada.

Promosi adalah salah satu unsur dalam bauran pemasaran (marketing mix) perusahaan yang didayagunakan untuk memberitahukan, membujuk dan mengingatkan tentang produk perusahaan" (Stanton, 2006:171). Strategi promosi sering digunakan sebagai salah satu cara untuk meningkatkan permintaan atau penjualan barang dan jasa yang ditawarkan, sehingga dapat meningkatkan laba yang diperoleh.

Selain kegiatan promosi juga dilakukan strategi pemasaran yang terkait dengan harga. Penetapan Harga (Price) merupakan salah satu elemen yang terdapat dalam bauran pemasaran yang berkenaan langsung dengan kebijakan strategis dan taktis mengenai tingkat harga, struktur diskon, dan syarat pembayaran.

Desain produk yang baik akan dapat meningkatkan jumlah dan harga jual dari produk, sehingga dapat meningkatkan keuntungan secara optimal. Akan tetapi, desain produk yang gagal mengakibatkan produk tidak terjual di pasaran.

Seiring dengan meningkatnya kebutuhan alat transportasi bagi perusahaan otomotif terutama dibidang sepeda motor, yang sangat dibutuhkan oleh banyak para konsumen, selain harganya yang terjangkau dan mudah perawatannya. Pertumbuhan konsumen sepeda motor meningkat luar biasa. Di tengah-tengah persaingan yang begitu tajam akibat banyaknya merek pendatang baru, sepeda motor Honda Beat yang sudah lama berada di Indonesia dengan segala keunggulannya, tetap mendominasi pasar setelah Honda Vario 
Series (110, 125 dan 150) dan sekaligus memenuhi kebutuhan angkutan yang tangguh, irit dan ekonomis.

Berdasarkan uraian diatas, maka peneliti tertarik untuk meneliti, Pengaruh Promosi, Harga dan Desain Terhadap Keputusan Pembelian Sepeda Motor Honda Beat (Studi Kasus : Pengguna Sepeda Motor Honda Beat Pada Masyarakat Kecamatan Medan Tembung).

\section{TINJAUAN PUSTAKA}

\section{A. Pengertian Promosi}

Promosi merupakan salah satu komponen dari bauran pemasaran (Product, Price, Place, Promotion) untuk mempengaruhi konsumen sasarannya. Pengertian promosi menurut para ahli:

1. Menurut Swastha (2000:222), promosi dipandang sebagai arus informasi atau persuasi satu arah yang di buat untuk mempengaruhi seseorang atau organisasi kepada tindakan yang menciptakan pertukaran dalam pemasaran.

2. Menurut Boone dan Kurtz (2002:129) promosi adalah proses menginformasikan, membujuk,dan mempengaruhi suatu keputusan pembelian.

3. Menurut Kismono (2001:374), promosi adalah usaha yang dilakukan pasar untuk mempengaruhi pihak lain agar berpartisipasi dalam kegiatan pertukaran.

Dari defenisi di atas disimpulkan, promosi adalah tindakan menginformasikan atau mengingatkan tentang spesifikasi produk atau merek.

Adapun Fungsi Promosi adalah Kotler (2007), 5 (lima) fungsi promosi yaitu:

1. Informing (memberikan informasi). Promosi membuat konsumen sadar akan produk-produk baru, mendidik mereka tentang berbagai fitur dan manfaat merek, serta memfasilitasi penciptaan citra sebuah perusahaan yang menghasilkan produk atau jasa.

2. Persuading (membujuk). Media promosi atau iklan yang baik akan mampu mempersuasi pelanggan untuk mencoba produk dan jasa yang ditawarkan.

3. Reminding (mengingatkan). Saat kebutuhan muncul, yang berhubungan dengan produk dan jasa yang diiklankan, dampak promosi di masa lalu memungkinkan merek pengiklan hadir di benak konsumen.

4. Adding Value (menambah nilai). Terdapat tiga cara perusahaan member nilai tambah bagi penawaran-penawaran mereka, inovasi, penyempurnaan kualitas, atau mengubah persepsi konsumen.

5. Assisting (mendampingi upaya-upaya lain dari perusahaan). Iklan merupakan salah satu alat promosi. Iklan dapat mengawasi proses penjualan produk-produk perusahaan dan memberikan pendahuluan yang bernilai bagi wiraniaga sebelum melakukan kontrak personal dengan pelanggan yang prospektif.

\section{B. Indikator Promosi}

Hasil penelitian Achidah, Warso dan Hasiolan (2016) menunjukkan indikator promosi yaitu : Kuantitas penayangan iklan di media promosi, Kualitas penyampaian pesan dalam penayangan iklan di media promosi, Jangkauan promosi, Menawarkan hadiah yang menarik pada transaksi pembelian produk tertentu dan: Melakukan penawaran khusus dalam jangka tertentu. 


\section{Harga}

Menurut Kotler (2001), keputusan harga dipengaruhi :

1. Konsumen sasaran. Konsumen sasaran adalah konsumen tingkat atas maka perusahaan akan cenderung menetapkan harga yang tinggi.

2. Permintaan konsumen. Jika terjadi permintaan yang cukup tinggi terhadap suatu produk dan jumlah barang yang tersedia sedikit maka perusahaan cenderung menetapkan harga cukup tinggi.

3. Pesaing . Jika dalam suatu pasar terdapat banyak pesaing yang menjual produk yang sejenis, produsen akan menetapkan harga yang rendah atau bersaing.

Berdasarkan pada penelitian-penelitian tersebut diatas maka variabel harga dapat dibentuk dari lima indikator, yaitu ; Harga sesuai dengan yang disampaikan dibrosurm : Keterjangkauan harga, Kesesuaian harga dengan kualitas produkm, Daya saing harga, Kesesuaian harga dengan manfaat.

\section{Desain Produk}

Desain Produk adalah sebagai alat manajemen untuk menterjemahkan hasil kegiatan penelitian dan pengembangan yang dilakukan sebelum menjadi rangcangan yang nyata yang akan diproduksi dan dijual dengan menghasilkan laba.

Desain produk salah satu unsur memajukan industri agar hasil industri produk tersebut dapat diterima oleh masyarakat, karena produk yang mereka dapatkan mempunyai kualitas baik, harga terjangkau, desain yang menarik, mendapatkan jaminan dan sebagainya.

Hasil penelitian Achidah, Warso dan Hasiholan (2016) menunjukkan indikator desain produk, yaitu: Model terbaru, Variasi desain, Desain mengikuti trend, Daya tarik bentuk lampu utama dan mampu member penerangan yang diperlukan dan Daya tarik pilihan warna.

\section{E. Proses Pengambilan Keputusan Pembelian}

Menurut Kotler dan Armstrong (2001), ada lima tahapan keputusan pembelian yaitu :

1. Pengenalan Kebutuhan. Proses pembelian oleh konsumen diawali sejak pembeli mengenali kebutuhan atau masalah.

2. Pencarian Informasi. Setelah konsumen yang terangsang kebutuhannya, konsumen akan terdorong untuk mencari informasi yang lebih banyak. Orang lebih peka terhadap informasi produk.

3. Evaluasi Alternatif. Evaluasi umunya mencerminkan keyakinan dan sikap yang mempengaruhi perilaku pembelian mereka. Keyakinan (belief) adalah gambaran pemikiran yang dianut seseorang tentang gambaran sesuatu.

4. Keputusan Pembelian. Dalam suatu kasus pembelian, konsumen bisa mengambil beberapa sub keputusan, meliputi merk, pemasok, jumlah, waktu pelaksanaan dan metode pembayaran. untuk produk-produk yang komplek akan membutuhkan pertimbangan yang pajang sebelum memutuskan pembelian..

5. Perilaku Pasca Pembelian. Setelah pembelian dilakukan, konsumen akan selalu siaga terhadap informasi yang mendukung keputusannya.

\section{F. Indikator Keputusan Pembelian}

Terdapat empat indikator untuk menentukan keputusan pembelian yaitu:

1. Kemantapan pada sebuah produk. Dalam melakukan pembelian, konsumen akan memilih salah satu dari beberapa alternatif yang ada. Pilihan tersebut didasarkan pada kualitas, mutu, harga yang terjangkau, dan faktor-faktor lain yang dapat memantapkan keinginan konsumen untuk membeli produk apakah produk tersebut benar- benar ingin digunakan atau dibutuhkan.

2. Kebiasaan dalam membeli produk. Kebiasaan konsumen dalam membeli produk juga 


\section{Volume 19 Nomor 1}

berpengaruh terhadap keputusan pembelian. Konsumen merasa produk tersebut sudah terlalu melekat di benak mereka karena mereka sudah merasakan manfaat dari produk tersebut.

3. Memberikan rekomendasi kepada orang lain. Dalam melakukan pembelian, jika konsumen mendapatkan manfaat yang sesuai dengan sebuah produk, mereka pasti akan akan membelinya.

4. Merekomendasikan produk tersebut dengan orang lain. Mereka ingin orang lain juga merasakan bahwa produk tersebut sangat bagus dan lebih baik dari produk lain.

Sedangkan hasil penelitian Achidah, dan Hasiolan (2016), indikator keputusan pembelian, yaitu: Keinginan untuk membeli produk, Prioritas pembelian pada produk tersebut, Rekomendasi dari orang-orang terdekat, Pertimbangan kebutuhan dari produk dan Keinginan membeli ulang.

Tabel 1. Penelitian Sebelumnya

\begin{tabular}{|c|c|c|c|}
\hline Pengarang & Variabel & Metode & Hasil/kesimpulan \\
\hline $\begin{array}{ll}\text { Bayu } & \text { yulianto, } \\
(2013) & \end{array}$ & $\begin{array}{l}\text { Pengaruh produk, harga, } \\
\text { promosi, layanan terhadap } \\
\text { keputusan } \\
\text { membeli } \text { konsumen } \\
\text { Kawasaki }\end{array}$ & $\begin{array}{l}\text { Regresi } \\
\text { berganda }\end{array}$ & $\begin{array}{l}\text { Terdapat pengaruh yang } \\
\text { positif dan signifikan antara } \\
\text { produk, harga, promosi, } \\
\text { layanan terhadap keputusan } \\
\text { konsumen membeli sepeda } \\
\text { motor Kawasaki }\end{array}$ \\
\hline $\begin{array}{l}\text { Ricky andi } \\
\text { Ervanto, (2013) }\end{array}$ & $\begin{array}{l}\text { Pengaruh produk, harga } \\
\text { dan promosi terhadap } \\
\text { keputusan pembelian } \\
\text { sepeda motor Yamaha di } \\
\text { PT. Harpindo Jaya } \\
\text { Sampangan Semarang }\end{array}$ & $\begin{array}{l}\text { Regresi } \\
\text { berganda }\end{array}$ & $\begin{array}{l}\text { Terdapat pengaruh yang } \\
\text { positif dan signifikan antara } \\
\text { produk, harga dan promosi } \\
\text { terhadap keputusan pembelian } \\
\text { sepeda motor Yamaha di PT. } \\
\text { Harpido Jaya Sampangan } \\
\text { Semarang }\end{array}$ \\
\hline $\begin{array}{l}\text { Rosa } \\
\text { Rachmaningrum } \\
\text { Dan Drs. } \mathrm{H} . \\
\text { Mudiantono, } \mathrm{M} . \\
\text { Sc, (2011) }\end{array}$ & $\begin{array}{l}\text { Analisis pengaruh produk, } \\
\text { merek, harga, dan } \\
\text { promosi } \\
\text { keputusan terhadap } \\
\text { sepeda motor Honda Beat }\end{array}$ & $\begin{array}{l}\text { Regresi } \\
\text { berganda }\end{array}$ & $\begin{array}{l}\text { Terdapat pengaruh yang } \\
\text { positif dan signifikan antara } \\
\text { Produk, merek, harga, dan } \\
\text { promosi terhadap keputusan } \\
\text { pembelian sepeda motor } \\
\text { Honda Beat }\end{array}$ \\
\hline $\begin{array}{l}\text { Aci Krismanti dan } \\
\text { Nunik } \\
\text { Kusnilawati, } \\
\text { (2013) }\end{array}$ & $\begin{array}{l}\text { Analisis pengarui harga, } \\
\text { promosi dan desain produk } \\
\text { terhadap } \\
\text { keputusan terhadap } \\
\text { sepeda motor Honda Non } \\
\text { Matic }\end{array}$ & $\begin{array}{l}\text { Regresi } \\
\text { berganda }\end{array}$ & $\begin{array}{l}\text { Terdapat pengaruh yang } \\
\text { positif dan signifikan antara } \\
\text { harga, promosi dan desain } \\
\text { produk terhadap keputusan } \\
\text { pembelian sepeda motor } \\
\text { Honda non Matic }\end{array}$ \\
\hline
\end{tabular}

\section{G. Kerangka Pemikiran Teoritis}

Gambar 1. Kerangka Pemikiran Teoritis

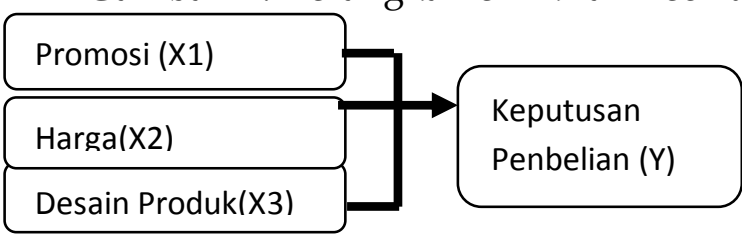

Sumber : Dikembangkan sendiri 


\section{METODE PENELITIAN}

\section{A. Populasi dan Sampel}

Populasi penelitian adalah seluruh masyarakat Kecamatan Medan Tembung. Sampel penelitian ini sebagian dari anggota populasi. Berdasarkan tingkat keyakinan $95 \%(\alpha=5 \%$, $\left.\mathrm{Z}^{1} / 2 \mathrm{\alpha}=1,96\right)$, kesalahan maksimum $(\varepsilon)=0,1$ dan standar deviasi $(\sigma)=0,5$ maka rumus penentuan sampel (Sugiyono (2005) :

$$
\begin{aligned}
n & =\left(\frac{z_{x / 2^{2}} \times \sigma}{E}\right)^{2} \\
& =\left(\frac{1,96 \times 0,5}{0,1}\right)^{2} \\
& =96,04 \text { orang }
\end{aligned}
$$

Maka jumlah sampel yang dibutuhkan (n) $=96$ orang.

\section{B. Operasionalisasi Variabel}

1. Variabel terikat $(Y)$ yaitu variabel yang dipengaruhi oleh variabel bebasnya. Dalam penelitian ini sebagai variabel terikat yaitu keputusan pembelian yang merupakan suatu kegiatan individu yang secara langsung terlibat dalam mendapatkan dan mempergu nakan barang yang ditawarkan.

2. Variabel bebas $(X)$ yaitu variabel yang mempengaruhi variabel terikatnya. Dalam penelitian ini terdapat 3(tiga) variabel bebas yaitu :

a. Variabel Promosi (X1) merupakan salah satu komponen dari bauran pemasaran untuk mempengaruhi konsumen sasarannya.

b. Variabel Harga (X2) yaitu merupakan salah satu komponen dari bauran pemasaran untuk mempengaruhi konsumen sasarannya.

c. Variabel Desain Produk (X3) yaitu salah satu unsur memajukan industri agar hasil industri produk tersebut dapat diterima oleh masyarakat, mempunyai kualitas baik, harga terjangkau, desain yang menarik, mendapatkan jaminan dan sebagainya.

\section{Teknik Pengumpulan Data}

Teknik pengumpulan data :

1. Wawancara. Wawancara merupakan teknik pengumpulan data dalam metode survei yang menggunakan pertanyaan secara lisan kepada subyek penelitian.

2. Koeisioner. Koesioner merupakan metode pengumpulan data yang diperoleh dari jawaban yang diberikan responden berdasarkan daftar pertanyaan yang telah disusun sebelumnya.

\section{Teknik Analisis}

Teknik analisis data dengan regresi linier berganda dengan persamaan :

$Y=\beta_{0}+\beta_{1} X 1+\beta_{2} X 2+\beta_{3} X 3+\beta_{0} X 4+$ ei

Keterangan: $Y=$ Variabel Terikat

$\mathrm{Ei}=$ Kesalahan dalam estimasi

b4 = Koefisien Regresi.
$\mathrm{X} 1, \mathrm{X} 2$ dan $\mathrm{X} 3=$ Variabel Bebas

$\mathrm{Bo}=$ Konstanta, $\mathrm{b} 1, \mathrm{~b} 2, \mathrm{~b} 3$

Persamaan regresi linier berganda tersebut diaplikasikan dengan persamaan :

$Y=\beta_{0}+\beta_{1} X 1+\beta_{2} X 2+\beta_{3} X 3+\beta_{0} X 4+$ ei

Keterangan: $Y=$ Keputusan Pembelian

$\mathrm{X} 2=$ Harga

$\mathrm{Ei}=$ Kesalahan dalam estimasi

b1,b2,b3, b4 = Koefisien Regresi.
$\mathrm{X} 1$ = Promosi

X3 = Desain Produk

Bo $=$ Konstanta

Membuktikan hipotesis dengan uji $\mathrm{F}$ dan $\mathrm{t}$. 


\section{HASIL PENELITIAN}

\section{A. Responden Menurut Jenis Kelamin}

Hasil penelitian menunjukan, bahwa responden yang diteliti di Kecamatan Medan

Tembung lebih dominan kaum laki-laki daripada perempuan.

1. Responden Menurut Jumlah Pendapatan. Hasil penelitian menunjukan, bahwa responden yang diteliti di Kecamatan Medan Tembung lebih dominan yang berpendapatan 2,1 juta - 3 juta sebesar 36,5\%.

2. Responden Menurut Tingkat Pendidikan. Berdasarkan hasil menunjukan, bahwa responden yang diteliti di Kecamatan Medan Tembung lebih dominan tingkat pendidikannya SMU sebesar 31,3\%.

\section{B. Persamaan Regresi Berganda}

Hasil persamaan regresi :

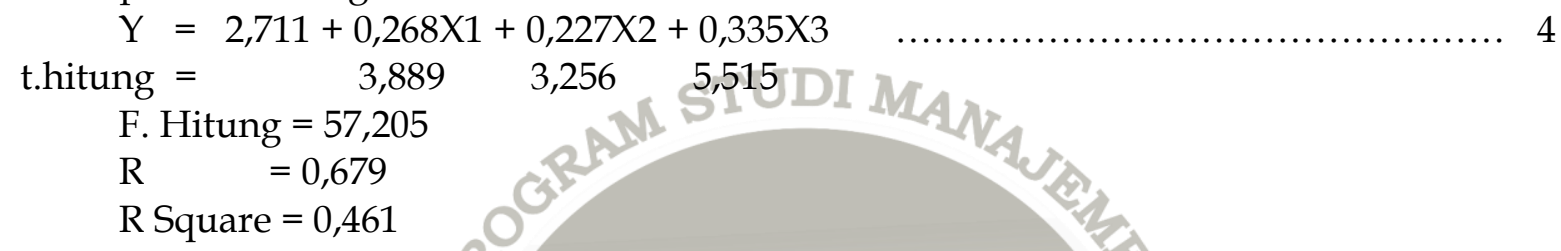

\section{Keterangan :}

a : Nilai konstanta sebesar 2,711 bearti jika promosi $\left(X_{1}\right)$, harga $\left(X_{2}\right)$ dan desain $\left(X_{3}\right)$ dianggap bernilai nol atau tidak ada maka nilai keputusan pembelian sebesar 2,711 .

b1 :Variabel promosi $\left(\mathrm{X}_{1}\right)$ berpengaruh positif terhadap keputusan pembelian dengan nilai koefisien sebesar 0,268 . Artinya variabel promosi $\left(\mathrm{X}_{1}\right)$ meningkat 1 satuan dengan asumsi variabel harga $\left(\mathrm{X}_{2}\right)$ dan desain $\left(\mathrm{X}_{3}\right)$ dianggap tetap, maka keputusan pembelian Sepeda Motor Honda Beat (Y) akan meningkat sebesar 0,268.

b2 Variabel harga $\left(\mathrm{X}_{2}\right)$ berpengaruh positif terhadap keputusan pembelian dengan nilai koefisien sebesar 0,227 . Artinya variabel harga $\left(X_{2}\right)$ meningkat 1 satuan dengan asumsi variabel promosi (X1) dan Desain (X3) dianggap tetap, maka keputusan pembelian akan meningkat sebesar 0,227.

b3 Variabel Desain (X3) berpengaruh positif terhadap keputusan pembelian dengan nilai koefisien sebesar 0,335 . Artinya variabel desain (X3) meningkat 1 satuan dengan asumsi variabel promosi $\left(X_{1}\right)$ dan harga $\left(X_{2}\right)$ dianggap tetap, maka keputusan pembelian akan meningkat sebesar 0,335.

Berdasarkan besaran koefisien regresi, ternyata dari ketiga variabel yang lebih dominan pengaruhnya terhadap keputusan pembelian yaitu variabel desain produk.

\section{Uji t}

Nilai $\mathrm{t}$ hitung variabel promosi, harga dan desain produk terhadap keputusan pembelian lebih besar dari nilai t. tabel Dengan hipotesis yang menyatakan bahwa promosi, harga dan desain produk memiliki pengaruh positif yang signifikan terhadap keputusan pembelian dapat diterima. Hipotesis diterima.

\section{Uji F}

Hasil pengujian diperoleh nilai $\mathrm{F}$ hitung lebih besar dari $\mathrm{F}$ tabel. Hipotesis yang menyatakan bahwa promosi, harga dan desain secara bersama-sama memiliki pengaruh yang signifikan terhadap keputusan pembelian. 


\section{E. Uji Determinasi}

Hasil perhitungan regresi dapat diketahui bahwa koefisien determinasi (adjusted R2) yang diperoleh sebesar 0,453. Hal ini berarti 45,3\% keputusan pembelian dipengaruhi oleh promosi, harga dan desain produk sedangkan $54,7 \%$ dipengaruhi oleh variabel lain yang tidak dijelaskan dalam model regresi ini .

\section{KESIMPULAN}

1. Berdasarkan analisis secara parsial, ternyata hasil penelitian membuktikan bahwa semua variabel independen (promosi, harga dan desain) mempunyai pengaruh positif terhadap variabel dependen yaitu keputusan pembelian sepeda motor Honda Beat di Kecamatan Medan Tembung.

2. Berdasarkan pengujian secara simultan, ternyata hasil peneliti membuktikan bahwa semua variabel independen (Promosi, harga dan desain) secara simultan mempunyai pengaruh yang signifikan terhadap variabel dependen yaitu keputusan pembelian. Dibuktikan dengan hasil F hitung $(57,205)$

3. Hasil pengujian regresi berganda menunjukkan bahwa dari semua variabel independen (promosi, harga dan desain) itu berpengaruh positif terhadap keputusan pembelian. Dan dari pengaruh positif terbesar terhadap keputusan pembelian sepeda motor Honda Beat di Kecamatan Medan Tembung adalah pada variabel desain (X3) hal ini ditunjukkan bahwa dari nilai koefisien regresi adalah sebesar 0,335 , kemudian diikuti oleh variabel promosi $\left(\mathrm{X}_{1}\right)$ yang ditunjukkan dari nilai koefisien regresinya adalah sebesar 0,268 , dan yang terendah adalah variabel harga $\left(X_{2}\right)$ yang ditunjukkan dengan nilai koefisien regresi sebesar 0,227 .

\section{DAFTAR PUSTAKA}

Achidah Nur, M Mukery Warso dan Leonardo Budi Hasiolan, Journal of Management, Vol. 2 No. 2, Maret 2016

Assauri, Sofjan. 2013. Manajemen Pemasaran. Jakarta :Rajawali Pers.

Boyd, Harper W, 2000, Manajemen pemasaran, Edisi Kedua, Erlangga, Jakarta

Buchory, Achmad Herry \& Saladin Djaslim (2010),.Manajemen Pemasaran: Edisi Pertama.Bandung:Linda Karya

David, Downey, 2002, Manajemen Agribisnis, Buku Keempat, Erlangga, Jakarta.

Kismono, Gugup. 2001, Pengantar Bisnis, . Edisi Pertama. Yogyakarta : BPFE.

Kotler, Philip, dkk, 2000, Manajemen Pemasaran dengan pemasaran efektikf dan Pofitable, cetakan Kedua, Gramedia Pusat Utama, Jakarta.

Kotler, Philip. 2005, Manajamen Pemasaran, Jilid 1 dan 2. Jakarta: PT. Indeks Kelompok Gramedia.

Kotler, Philip dan Armstrong, Gary, 2001. Prinsip-prinsip Pemasaran, Jilid 1, Alih Bahasa: Damos Sihombing, Edisi Kedelapan, Jakarta : Erlangga.

Jakarta.

2004, Dasar-dasar Pemasaran, Edisi Kesembilan, PT. Indeks, 
Volume 19 Nomor 1

2006, Principles of Marketing. 11 th Edition. New Jersey: Prentice Hall. Pearson Education, Inc., Upper Saddle River, New Jersey.

Kotler dan Keller, 2007, Manajemen Pemasaran, Edisi 12, Jilid 1, PT.Indeks, Jakarta.

Sugiyono, 2005. Metode Penelitian Bisnis, Cetakan Keenam, Bandung: Alfabeta.

Stanton, Wiliam J. (2006), Prinsip Pemasaran . alih bahasa:Yohannes Lamarto. edisi ketujuh. Jakarta: Penerbit Erlangga.

Stanton, William. J, 2000, Prinsip Pemasaran, Edisi Revisi, Erlangga, Jakarta.

Sugiyono, 2004. Metode Penelitian Bisnis, Cetakan Keenam, Bandung: Alfabeta.

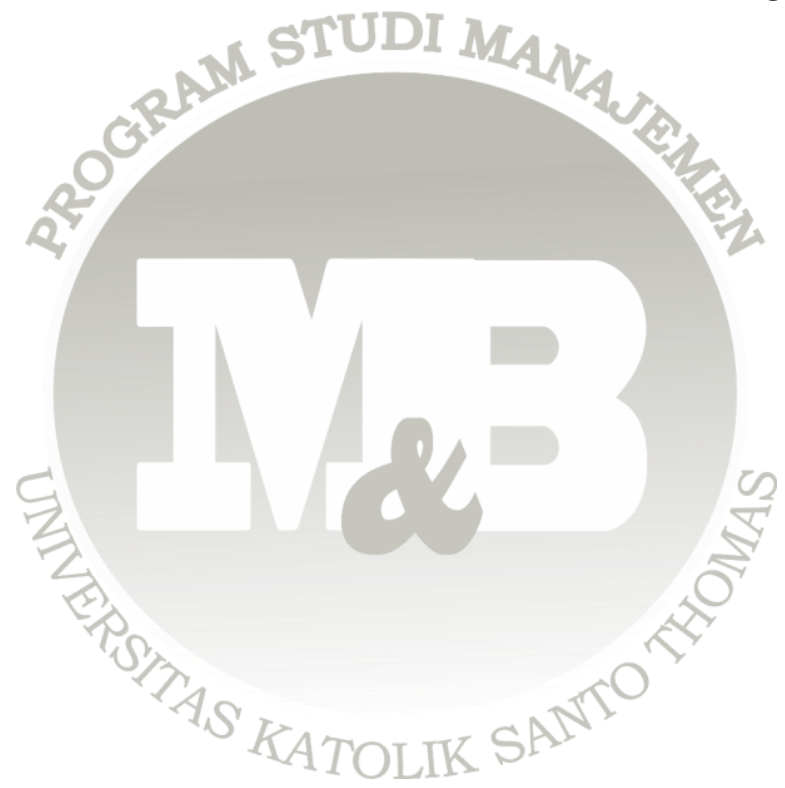

